\title{
Short Communication. Glycogenosis Ib: Neutrophil Microbicidal Defects Due to Impaired Hexose Monophosphate Shunt
}

\author{
REINHARD SEGER, ${ }^{(14)}$ BEAT STEINMANN, LOUIS TIEFENAUER, TEIICHI MATSUNAGA, AND \\ RICHARD GITZELMANN \\ Department of Pediatrics, Divisions of Hematology/Immunology and Metabolism, University of Zürich, \\ CH-8032 Zurich, Switzerland
}

\begin{abstract}
Summary
We studied neutrophil microbicidal function and oxidative metabolic activity in a patient with glycogenosis Ib. The intracellular killing defect and the respiratory burst abnormality in gycogenosis Ib neutrophils were confirmed. The impaired oxygen-dependent microbicidal activity was shown to result from impaired hexose monophosphate shunt activity (impaired endogenous NADPH synthesis) and could be corrected by homogenization of the cells, followed by the addition of exogenous NADPH. Our data are thus consistent with a possible role for glucose-6-phosphate transport in neutrophil microbicidal function. We recommend a continuous prophylaxis with co-trimoxazole in patients with glycogen storage disease Ib.
\end{abstract}

Abbreviations

GSD, glycogen storage disease

HMP, hexose monophosphate

NBT, nitroblue tetrazolium

PMN, polymorphonuclear neutrophils

Patients with GSD Ib suffer from recurrent infections whereas patients with GSD Ia do not. In GSD Ib, quantitative anomalies of PMN have recently been documented, such as neutropenia, diminished random and directed PMN migration $(1,2,6)$, decreased phagocytosis-stimulated oxygen consumption (3), decreased NBT reduction (6), and a defect in PMN bactericidal activity (6). The relationship of these PMN anomalies to the primary enzyme defect and/or to the secondary metabolic consequences of the genetic defect remained at first unclear. A defective glucose-6-phosphate transport system as postulated by Narisawa et al. (8) for liver, and thus limited availability of this substrate for the hexose monophosphate shunt was then suggested by Heyne and Gahr (4). We now demonstrate defective HMP shunt activity in the PMN of a patient suffering from GSD Ib.

\section{MATERIALS AND METHODS}

PMN functions were investigated in one patient with GSD Ib, in healthy adults, and in contrast patients (GSD Ia). GSD was documented in biopsied liver: GSD Ib by a normal amount of latent, GSD Ia by absent glucose-6-phosphatase activity. The patient with GSD Ib, aged $13 \mathrm{yr}$, had suffered from numerous cutaneous infections. Neutrophil counts ranged from $0-6000 / \mu \mathrm{l}$. His PMN were studied when counts were from $1650-2340 / \mu 1$. PMN were prepared by dextran sedimentation followed by Fi-
coll-Hypaque centrifugation. This technique routinely resulted in cell populations containing $>95 \%$ PMN. Oxygen consumption was measured polarographically with an oxygen-sensitive electrode. $\mathrm{O}_{2}^{-}$generation was determined by measuring the superoxide dismutase inhibitable reduction of cytochrome $\mathrm{c}$ as described before (9). HMP shunt activity was measured by determining the amount of $\left[1-{ }^{14} \mathrm{C}\right]$ glucose converted to $\left[{ }^{14} \mathrm{CO}_{2}\right]$ as described by Newburger and co-workers (10). The preparation of a mixed membrane fraction (particulate fraction) of PMN was performed according to Suzuki and Lehrer (12).

\section{RESULTS}

Random and directed PMN migration under agarose toward zymosan-activated serum was diminished (mean, 73 and $61 \%$ of control, respectively) in the GSD Ib patient. His PMN had decreased oxygen consumption compared with controls and GSD Ia patients, using both a soluble (phorbol myristate, Fig. 1) and a particulate (opsonised zymosan; results not shown) stimulant. Although phagocytosis of opsonised baker's yeast proceeded normally, there was a significant defect in PMN bactericidal activity with Staphylococcus aureus, with $<50 \%$ killing at 120 min (Fig. 1).

Experiments designed to find a cause for the respiratory burst anomaly and for the impaired bactericidal activity suggested deficient NADPH synthesis. Membrane activation as evidenced by depolarization of the resting membrane potential and by the lag time of $\mathrm{O}_{2}^{-}$production was normal in PMN as was glucose6-phosphate dehydrogenase activity in red cells. In contrast, HMP shunt activity after stimulation with methylene blue was decreased to $28 \%$ of controls in the GSD Ib patient but not in a patient wtih GSD Ia. Although $\mathrm{O}_{2}^{-}$production with whole cells (with endogenous NADPH only) was clearly deficient in GSD Ib ( $26 \%$ of controls), it was normalized after homogenization of the cells, followed by the addition of $200 \mu \mathrm{M}$ exogenous NADPH (Table 1).

\section{DISCUSSION}

The decreased PMN bactericidal activity in this patient suffering from GSD Ib is caused by insufficient NADPH synthesis due to an impaired HMP shunt. This results in a diminished supply of reducing equivalents needed for the generation of microbicidal oxygen metabolites. HMP shunt activity could be impaired in GSD Ib if the substrate glucose-6-phosphate were unavailable for the enzymes of the shunt as it is for glucose-6-phosphatase in hepatocytes. Our findings thus bring into focus the association of GSD Ib, a defect of glucose-6-phosphate transport (7), im- 


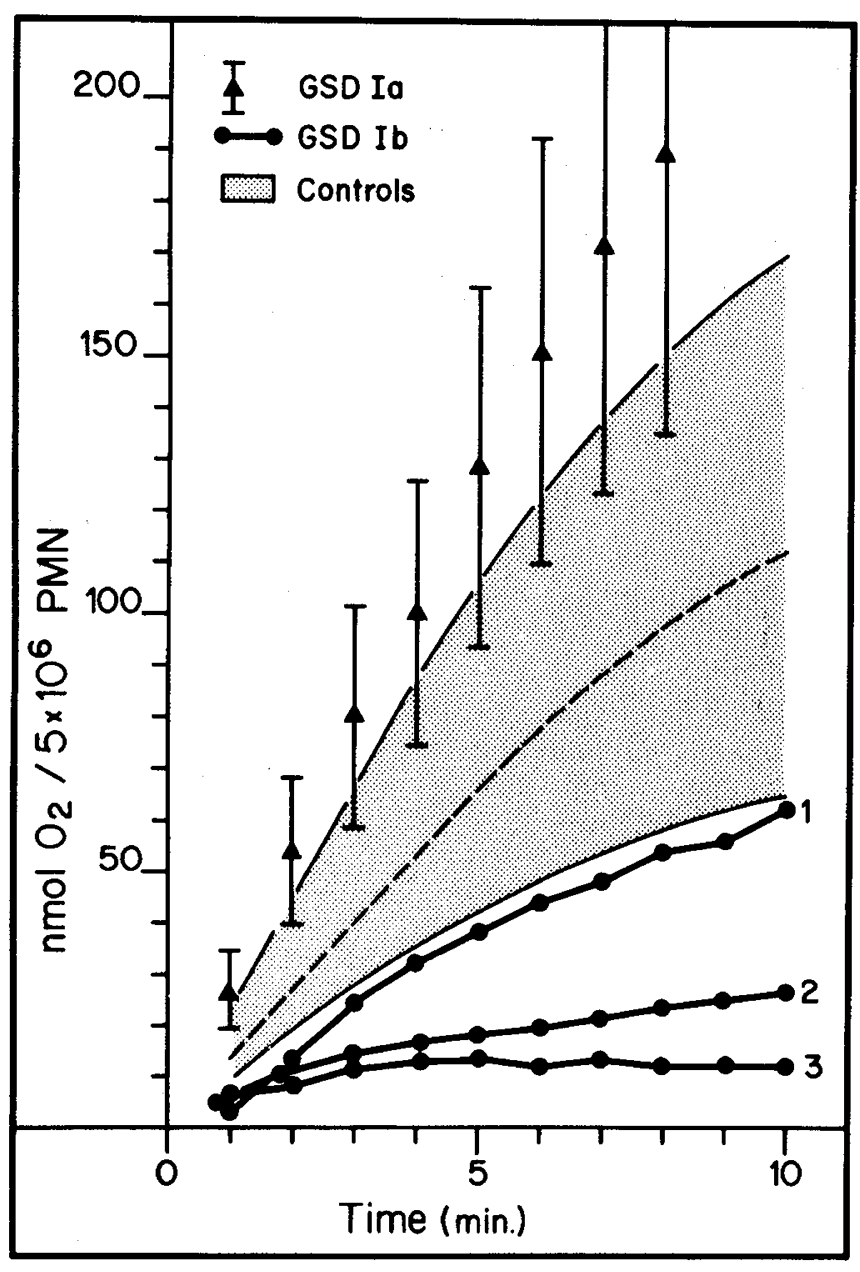

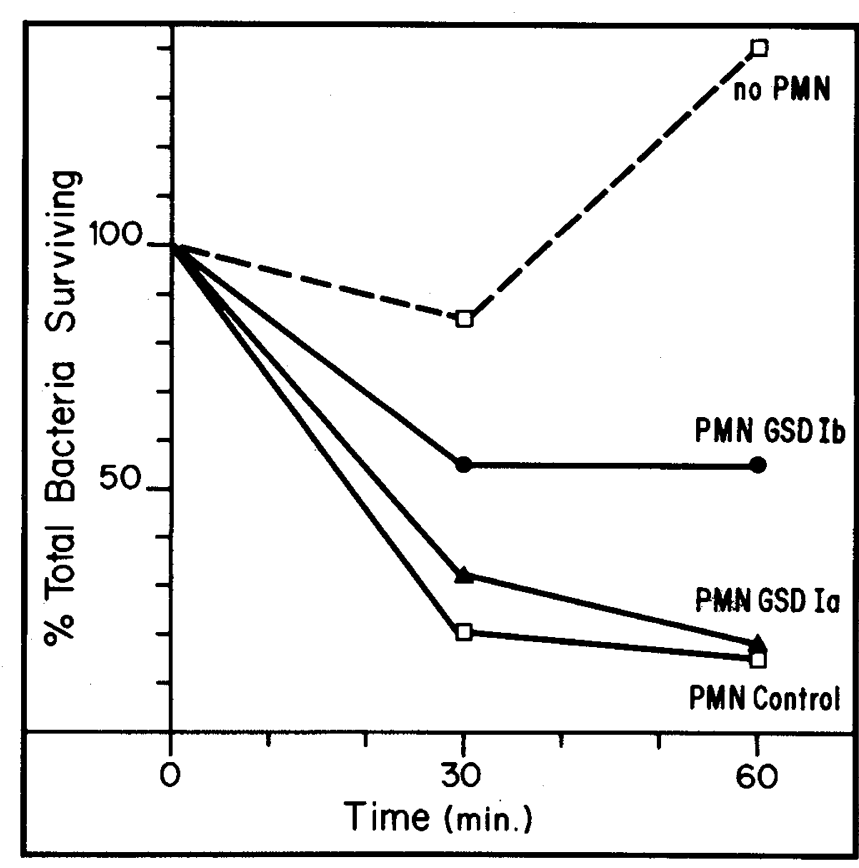

Fig. 1. Polymorphonuclear neutrophils (PMN) microbicidal functions in a patient with glycogen storage disease (GSD) Ib, patient(s) with GSD Ia and control(s). Left hand panel, oxygen consumption after stimulation with phorbol myristate acetate $(1 \mu \mathrm{g} / \mathrm{ml})$. Results are expressed as $\bar{x} \pm 2 \mathrm{SD}$ in 10 controls, $\bar{x}+1 \mathrm{SD}$ in four GSD Ia patients, and as individual values on three different experimental days in the GSD Ib patient. Right hand panel, killing of Staphylococcus aureus (strain SG511). The ratio of bacteria: PMN was 1 , the concentrations of PMN and control serum $2.5 \times 10^{6} / \mathrm{ml}$ and $20 \%$, respectively. Results are expressed as mean of triplicates in a control, a GSD la and a GSD Ib patient, respectively.

Table 1. Hexose monophosphate shunt activity and $\mathrm{O}_{2}^{-}$production in glycogenosis $\mathrm{Ib}$ and $\mathrm{Ia}^{*}$

\begin{tabular}{|c|c|c|c|}
\hline & HMP shunt & \multicolumn{2}{|c|}{$\mathrm{O}_{2}^{-}$production } \\
\hline & Whole cells $\dagger$ & Whole cells $\ddagger$ (endogenous NADPH) & $\begin{array}{c}\text { Particulate fraction } \S(+200 \mu \mathrm{M} \\
\text { NADPH })\end{array}$ \\
\hline GSD Ib patient & $0.21 ; 0.32 ; 0.45$ & 2.44 & 3.90 \\
\hline GSD Ia patients & $0.88(n=1)$ & $9.21 \pm 2.19(n=4)$ & $3.20(n=1)$ \\
\hline Controls & $1.19 \pm 0.38(n=13)$ & $9.26 \pm 2.46(n=10)$ & $5.60 \pm 1.17(n=5)$ \\
\hline
\end{tabular}

* Results are expressed as means of duplicates of different experimental days, or as mean $\pm 1 \mathrm{SD}$ of $n$ different patients or controls.

$\dagger$ In nmol glucose oxidised/30 $\mathrm{min} \times 10^{6} \mathrm{PMN}$ after methylene blue $(1 \mathrm{mM})$ stimulation.

$\ddagger$ In $\mathrm{nmol} \mathrm{O}_{2}^{-}$produced $/ \mathrm{min} \times 10^{6} \mathrm{PMN}$ after phorbol myristate acetate $(1 \mu \mathrm{g} / \mathrm{ml})$ stimulation.

$\S$ In $\mathrm{nmol} \mathrm{O}_{2}^{-}$produced/min $\times \mathrm{mg}$ protein after phorbol myristate acetate $(1 \mu \mathrm{g} / \mathrm{ml})$ stimulation.

paired HMP shunt, and decreased $\mathrm{O}_{2}^{-}$production. It also draws attention to a possible role for glucose-6-phosphate transport in neutrophil microbicidal function. Because causal therapy for the intracellular killing defect in GSD Ib is not yet available, we recommend a continuous prophylaxis with co-trimoxazole previously shown to penetrate PMN (11) and to suppress infections in patients with other intracellular microbicidal defects e.g., chronic granulomatous disease (5).

\section{REFERENCES AND NOTES}

1. Anderson, D. C., Mace, M. L., Brinkley, B. R., Martin, R. R., and Smith, C. W.: Recurrent infection in glycogenosis type Ib: abnormal neutrophil motility related to impaired redistribution of adhesion sites. J. Infect. Dis., 143: 447 (1981).
2. Beaudet, A. L., Anderson, D. C., Michels, V. V., Arion, W. J., and Lange, A. J.: Neutropenia and impaired neutrophil migration in type Ib glycogen storage disease. J. Pediatr., 97: 906 (1980).

3. Heyne, K. and Gahr, M.: Differentiation between glycogenosis types Ia and $\mathrm{Ib}$ by measurement of extra respiration during phagocytosis by polymorphonuclear leukocytes? Eur. J. Pediatr., 133: 69 (1980).

4. Heyne, K. and Gahr, M.: Phagocytotic extra-respiration: differences between cases of glycogenosis type Ia and Ib. Eur. J. Pediatr., 133: 186 (1980).

5. Kobayashi, Y., Amano, D., Ueda, K., Kagosaki, Y., and Usui, T.: Treatment of seven cases of chronic granulomatous disease with sulfamethoxazoletrimethoprim (SMX/TMP). Eur. J. Pediatr., 127: 247 (1978).

6. Koven, N. L., Clark, M. M., Cody,C. S., Stanley, C. A., Baker, L., and Douglas, S. D.: Impaired chemotaxis and neutrophil (PMN) function in glycogenosis (GSD) Ib. Pediatr. Res. (abstract), 14: 226A (1981).

7. Lange, A. J., Arion, W. J., and Beaudet, A. L.: Type Ib glycogen storage disease is caused by a defect in the glucose-6-phosphate translocase of the microsomal glucose-6-phosphatase system. J. Biol. Chem., 255: 8381 (1980).

8. Narisawa, K., Igarashi, Y., Otomo, H., and Tada, K.: A new variant of glycogen 
storage disease type I probably due to a defect in the glucose-6-phosphate transport system. Biochem. Biophys. Res. Commun., 83: 1360 (1978).

9. Newburger, P. E., Chovaniec, M. E., and Cohen, H. J.: Activity and activation of the granulocyte superoxide-generating system. Blood, 55: 85 (1980).

10. Newburger, P. E., Pagano, J. S., Greenberger, J. S., Karpas, A., and Cohen, H. J.: Dissociation of opsonised particle phagocytosis and respiratory burst activity in an Epstein-Barr-virus infected myeloid cell line. J. Cell Biol., 85: 549 (1980).

11. Seger, R. A., Baumgartner,S., Tiefenauer, L. X., and Gmünder,F. K.: Chronic granulomatous disease: effect of sulfamethoxazole/trimethoprim on neutro- phil microbicidal function. Helv. Paediatr. Acta, 36: 579 (1981).

12. Suzuki, Y. and Lehrer, R. I.: NAD(P)H oxidase activity in human neutrophils stimulated by phorbolmyristate acetate. J. Clin. Invest., 66: 1409 (1980).

13. This work was supported by grants from the Swiss National Science Foundation (3.884-0.81 and 3.853-0.81) and from the Schweizerische Krebsliga.

14. Requests for reprints should be addressed to: Dr. R. Seger, Kinderspital Zürich,Steinwiesstrasse 75, CH-8032 Zürich, Switzerland, phone 01-251 22 44.

15. Received for publication November 9, 1982.

16. Accepted for publication May 13, 1983.
0031-3998/84/1803-0299\$02.00/0

PEDIATRIC RESEARCH

Copyright (C) 1984 International Pediatric Research Foundation, Inc.
Vol. 18, No. 3, 1984 Printed in U.S.A.

\section{Letter to the Editor}

\section{HUGO CHIODI}

\section{Los Angeles County-University of Southern California Medical Center, Los Angeles, California, USA}

In their recent paper, "Development of hepatic fatty acid oxidation and ketogenesis in the newborn guinea pig," Stanley et al. (1) suggest that the role of carnitine in the development of fatty acid oxidation is very different in the rat when compared with the newborn guinea pig. Our studies on fatty liver degeneration in hypoxic newborn rats support the suggestion that a unique feature of the newborn rat is its lipid metabolism $(2,3$, $4,5)$.

A high percentage of newborn rats, kept at a simulated altitude of about $4600 \mathrm{~m}$ since they were 1-d-old, died between 10-15 days of age with severe fatty liver degeneration as shown by chemical, light, and electron microscopic studies (6). Fetuses from female rats kept under hypoxic conditions during pregnancy did not show any abnormalities. Out of 18 newborn guinea pigs kept under the same hypoxic conditions, only three died from fatty liver. Newborn rabbits did not show any changes in their livers. Newborn mice showed some lipid liver increase, but they survived without any apparent impairment to their health (Fig. 1). Hypoxic newborn rats sucked milk quantitatively and qualitatively similar to that of the controls. Perinatal rats did not show any abnormality in their lipid metabolism if made hypoxic

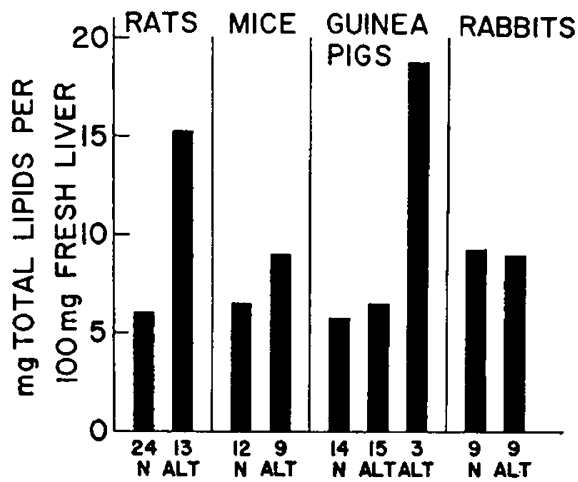

Fig. 1. Total lipids of the liver of normal and altitude suckling animals. Altitude animals were born or introduced into the altitude chamber when 1-d-old and remained there $14 \mathrm{~d}$. N, normals at $1260 \mathrm{~m}$ and Alt, rats at a simulated altitude of approximately $4700 \mathrm{~m}$. At the bottom of the bars, number of animals (from Ref. 3 ).

TABLE 1. Lipid content of liver, plasma, and carcass of hypoxic and normal control young rats fasted $16 \mathrm{hr}$

\begin{tabular}{|c|c|c|c|c|c|c|c|c|c|c|}
\hline & $\begin{array}{l}\text { No. of } \\
\text { Ani- } \\
\text { mals }\end{array}$ & Body Wt, $s$ & Hct, \% & $\begin{array}{c}\text { Total Lipids, } \\
\% \text { Liver Wet } \\
\text { Wt }\end{array}$ & $\begin{array}{l}\text { Triglycerides, } \\
\text { \% Liver } \\
\text { Total Lipids }\end{array}$ & $\begin{array}{c}\text { Plagma roual } \\
\text { Lipids, mel } \\
100 \mathrm{ml}\end{array}$ & $\begin{array}{l}\text { Trislycerides } \\
\text { \% Plasms } \\
\text { Total Lipids }\end{array}$ & $\begin{array}{l}\text { Plagme Free } \\
\text { Fatty Acids, } \\
\text { mEq /liter }\end{array}$ & $\begin{array}{l}\text { Total Lipides } \\
\text { \% Cercass Wt }\end{array}$ & $\begin{array}{l}\text { Triglycerides, } \\
\text { \% Carcases } \\
\text { Total Lipids }\end{array}$ \\
\hline $\begin{array}{l}7 \text { days old, } 6 \\
\text { days at approx } \\
4,700 \mathrm{~m}\end{array}$ & 6 & $12.2 \pm 0.1$ & $41.7 \pm 0.5$ & $7.1 \pm 0.7$ & & $1,013 \pm 98$ & & $0.9 \pm 0.1$ & & \\
\hline 6 days old, & 6 & $11.4 \pm 0.5$ & $38.5 \pm 1.0$ & $5.1 \pm 0.2$ & & $848 \pm 64$ & & $1.1 \pm 0.1$ & & \\
\hline $\begin{array}{l}10 \text { days old, } 9 \\
\text { days at approx } \\
4,700 \mathrm{~m}\end{array}$ & 7 & $10.9 \pm 0.3$ & $49.5 \pm 1.1$ & $9.1 \pm 0.4$ & $30.9 \pm 1.4$ & $973 \pm 55$ & $29.1 \pm 3.1$ & & $7.3 \pm 0.7$ & $83.5 \pm 11.9$ \\
\hline 11 days old, & 9 & & $40.2 \pm 0.5$ & $4.7 \pm 0.2$ & $16.5 \pm 1.5$ & $736 \pm 43$ & $8.5 \pm 1.0$ & $0.8 \pm 0.1$ & $5.8 \pm 0.8$ & $79.5 \pm 5.1$ \\
\hline $\begin{array}{l}14 \text { days old, } 13 \\
\text { days at approx } \\
4,700 \mathrm{~m}\end{array}$ & 8 & $20.0 \pm 1.4$ & $44.7 \pm 0.5$ & $10.6 \pm 0.9$ & $56.7 \pm 2.4$ & $1,110 \pm 144$ & $47.0 \pm 2.7$ & $1.4 \pm 0.1$ & $16.3 \pm 1.7$ & $87.6 \pm 2.3$ \\
\hline $\begin{array}{l}14 \text { days old, } \\
\text { normals }\end{array}$ & 7 & $27.9 \pm 0.6$ & $35.8 \pm 0.4$ & $5.5 \pm 0.1$ & $14.7 \pm 1.2$ & $924 \pm 39$ & $27.2 \pm 2.1$ & $1.6 \pm 0.1$ & $12.9 \pm 0.2$ & \\
\hline $\begin{array}{l}17 \text { days old, } 16 \\
\text { days at approx } \\
4,700 \mathrm{~m}\end{array}$ & 6 & $22.0 \pm 2.0$ & $42.9 \pm 1.2$ & & & $1,580 \pm 107$ & $55.9 \pm 3.2$ & $4.3 \pm 0.6$ & & \\
\hline $\begin{array}{l}18 \text { days old, } \\
\text { normals }\end{array}$ & 5 & $19.9 \pm 1.1$ & $39.8 \pm 0.4$ & $4.2 \pm 0.1$ & $17.6 \pm 1.8$ & $966 \pm 36$ & $11.9 \pm 2.4$ & $0.9 \pm 0.1$ & & \\
\hline
\end{tabular}

- Values are means \pm standard error.

Reproduced by permission of Federation of the American Society of Experimental Biologists. 